\title{
CONHECIMENTO TRADICIONAL COMO INSTRUMENTO PARA DINAMIZAÇÃo DO CURRÍCULO E ENSINO DE CIÊNCIAS
}

\author{
Maria Laura Souza Silva ${ }^{1}$, Geilsa Costa Santos Baptista ${ }^{2}$
}

1 Doutoranda em Ensino, Filosofia e História das Ciências. Docente da Coordenação de Engenharia Ambiental, IFBA (Instituto Federal de Educação, Ciência e Tecnologia - Campus Vitória da Conquista-BA.

2 Professora Titular do Departamento de Educação da Universidade Estadual de Feira de Santana-BA. Doutora em Ensino, Filosofia e História das Ciências. * Autor para correspondência: m.lauras02@hotmail.com

Recebido em 13 de março de 2018. Aceito em 20 de dezembro de 2018. Publicado em 31 de dezembro de 2018.

\begin{abstract}
REsumo - O presente artigo de revisão teórica tem o objetivo de apresentar a importância do conhecimento tradicional para tornar as aulas de ciências mais atrativas, levando em consideração o contexto cultural e socioambiental dos estudantes. Inicialmente, faz-se uma discussão de como a ciência ocidental se sobrepõe às demais formas de conhecimento, muitas vezes desconsiderando o conhecimento tradicional, tornando estanque e sem aplicação dos conteúdos científicos nos cotidianos dos estudantes. Um ensino de ciências, que leve em consideração apenas o conhecimento oriundo da ciência ocidental, sem considerar a importância do saber tradicional, perde a oportunidade de dialogar com outras formas de conhecimento, o que poderia enriquecer sobremaneira o currículo de ciências. O Pluralismo Epistemológico trabalha com o conhecimento tradicional, levando em consideração a importância da demarcação de saberes - o objetivo aqui não é "transformar" conhecimento tradicional em científico, mas mostrar que cada forma de conhecimento, através de métodos e concepções de vida diferentes, tem sua importância.
\end{abstract}

Palavras-chave: Conhecimento científico. Conhecimento tradicional. Ensino de CiÊnCias. DemarcaÇão de saberes. Currículo.

El Conocimiento Tradicional como Instrumento para la Dinamización del Plan de Estudios y la Enseñanza DE Ciencias

RESUMEN - El presente artículo de revisión teórica tiene como objetivo presentar la importancia del conocimiento tradicional para hacer las clases de ciencias más atractivas, teniendo en cuenta el contexto cultural y socioambiental de los estudiantes. Inicialmente, se hace una discusión de cómo la ciencia occidental se superpone a las demás formas de conocimiento, muchas veces desconsiderando el conocimiento tradicional, haciendo estancado y sin aplicación de los contenidos científicos del cotidiano de los estudiantes. Una enseñanza de ciencias, que tenga en cuenta sólo el conocimiento proveniente de la ciencia occidental, sin considerar la importancia del saber tradicional, pierde la oportunidad de dialogar con otras formas de conocimiento, lo que podría enriquecer sobre todo el currículo de ciencias. El Pluralismo Epistemológico trabaja con el conocimiento tradicional, teniendo en cuenta la importancia de la demarcación de saberes - el objetivo aquí no es "transformar" conocimiento tradicional en científico, sino mostrar que cada forma de conocimiento, a través de métodos y concepciones de vida diferentes tiene su importancia.

Palabras clave: Conocimiento científico. Conocimiento tradicional. Enseñanza de las ciencias. Demarcación de SABeres. Plan de estudios. 


\section{Traditional Knowledge as an instrument for dynamizing the Curriculum and Science Teaching}

Aвstract - The present theoretical review article aims to present the importance of traditional knowledge to make science classes more attractive, considering the cultural and social environment contexts of the students. Initially, a discussion is made of how Western science overlaps with other forms of knowledge, often disregarding traditional knowledge, making it stagnant and with no application of scientific content to students' daily lives. A science education that only considers the knowledge of Western science, without taking into account the importance of traditional knowledge, misses the opportunity to dialogue with other forms of knowledge, which could greatly enrich the Curriculum of Sciences. The Epistemological Pluralism works with traditional knowledge, taking into account the importance of the demarcation of knowledge. The objective is not to "transform" traditional knowledge into a scientific one, but to show that each form of knowledge, through different methods and conceptions of life, has its importance.

Keywords: Scientific knowledge. Traditional knowledge. Science teaching. Demarcation of Knowledge. Curriculum.

\section{INTRODUÇÃO}

O ensino de ciências nas escolas tem sido alvo de muitas críticas, tanto por parte dos estudantes, quanto por parte da academia, que, em geral, considera esse ensino descontextualizado, fora da realidade do educando. Uma das maiores críticas diz respeito aos conteúdos transmitidos em sala de aula, que apenas levam em consideração aquilo que vem formatado nos livros didáticos e que é considerado "científico" pela academia. Os estudantes, por sua vez, convivem, muitas vezes, com um conteúdo distante de sua realidade, que desrespeita as suas histórias de vida e suas culturas.

Guimarães (2007) afirma que falta ao processo educativo a perspectiva crítica de "ampliar o ambiente educativo para além dos muros da escola superando a fragmentação e a dualidade que tradicionalmente não se complementam entre educação formal (escolar) e não-formal". Diante desse contexto, é preciso demonstrar aos estudantes que a escola é um dos lugares onde se adquire conhecimento, porém, não pode ser considerado o único.

Uma alternativa para superar esse distanciamento entre escola e cultura, escola e cotidiano, seria a inserção do conhecimento advindo do próprio contexto histórico-cultural de cada grupo onde a escola está inserida, na sala de aula. Entendendo-se como "currículo" todo o acervo de conhecimentos trabalhados na escola, incluindo as formas de transmissão desses conhecimentos e as relações humanas construídas no cotidiano. O conhecimento tradicional, nesse sentido, contribuiria de forma efetiva para a superação da distância entre escola e comunidade, tornando-se um elemento importante para tornar o ensino de ciências algo estimulante, desafiador e inserido nos interesses do educando.

O conhecimento tradicional seria todo o conjunto de conhecimentos construídos pela humanidade através dos tempos, desde que o ser humano surgiu na história evolutiva, propiciando a este a sobrevivência neste planeta, desde os tempos das cavernas até os dias atuais. Para muitas comunidades, este conhecimento construído empiricamente pela humanidade, até hoje tem sido sua principal forma de sobrevivência. No Brasil, o decreto n. ${ }^{\circ}$ 6.040, de 7 de fevereiro de 2007, no seu Artigo 3, define as populações tradicionais como "povos e comunidades tradicionais", tratando esses grupos como:

Grupos culturalmente diferenciados e que se reconhecem como tais, que possuem formas próprias de organização social, que ocupam e usam territórios e recursos naturais como condição para sua reprodução cultural, social, religiosa, ancestral e econômica, utilizando conhecimentos, inovações e práticas gerados e transmitidos pela tradição (BRASIL 2007). 
Como exemplos de tais comunidades, poderíamos citar indígenas, quilombolas, ribeirinhas, costeiras e rurais. Esses grupos trazem consigo todo um acervo de conhecimentos que não é reconhecido como "ciência", pelo menos não como "ciência ocidental", mas que possui um valor intrínseco como forma de sobrevivência desses povos, além de representar a relação destes com a natureza. A inserção desses conhecimentos em sala de aula poderia reduzir o distanciamento entre a escola e o cotidiano. A etnobiologia se apresenta como um dos caminhos para a interlocução entre a ciência e o conhecimento tradicional, podendo se configurar como um instrumento de diálogo entre o saber local e o conhecimento científico. Santos-Fita e Costa-Neto (2007), consideram que a etnobiologia fornece um arcabouço teórico para interligar diferentes áreas das ciências sociais e naturais com outros sistemas de conhecimentos não acadêmicos.

Baptista $(2010$; 2012) argumenta que a etnobiologia pode contribuir para o ensino, a aprendizagem e a formação do professor de ciências. No ensino, porque ajuda os professores a investigar e compreender quais são os saberes culturais que os discentes carregam consigo para as salas de aula, o que o ajudará na construção de um ensino pautado no diálogo intercultural, entre a cultura da ciência e a cultura do estudante; na aprendizagem, porque ajudará os estudantes a verem significados nos conteúdos que estão sendo ensinados, quando eles poderão sentir-se motivados e interessados pelas aulas, pelo fato de os professores envolverem seus saberes no diálogo; pode contribuir na formação do professor, porque a etnobiologia, ao ajudá-lo a investigar e compreender os conhecimentos e práticas culturais dos estudantes e realização do diálogo intercultural, estará contribuindo para reflexões sobre e na prática pedagógica, o que auxiliará a identidade docente sensível à diversidade cultural.

A etnobiologia é um termo recente, surgido a partir de meados do século XX, para designar o conjunto de conhecimentos de comunidades tradicionais relacionados às plantas, aos animais, aos sistemas de classificação e à ecologia. Segundo Clément (1998), somente nas décadas de 50 e 60 é que as etnociências firmaram-se enquanto campos do conhecimento. Mas, ainda segundo esse autor, a etnobiologia, definida aqui como o estudo das ciências biológicas praticadas pelos vários grupos humanos, tem sua origem no final do século XIX, quando foram dados nomes diferentes para suas subdisciplinas, como botânica aplicada, etnobotânica e etnozoologia. Porém, o termo “etnobologia” surgiu em 1935, nos Estados Unidos (Castetter 1935).

As etnociências englobam importantes conceitos, estratégias de sobrevivência e de conservação da natureza construídos ao longo de milênios por povos tradicionais. Mas, na maioria das vezes, esses conhecimentos são ignorados pelo professor e, esse fato se agrava quando o estudante oriundo de uma comunidade tradicional, estuda em uma escola localizada num centro urbano. Baptista (2014) afirma que apesar do reconhecimento da ciência como uma entre as diversas culturas, o que prevalece na maioria das salas de aula de ciências é a prática pedagógica cientificista, centrada na transmissão e reprodução de conhecimentos científicos considerados como sendo os únicos verdadeiros, fora dos contextos da própria ciência e/ou das realidades dos estudantes. A autora chama a atenção para o fato de que estudantes de comunidades tradicionais e de sociedades urbanas apresentam realidades específicas, que devem ser consideradas:

O contexto no qual se encontra o ensino de ciências no Brasil é ainda mais agravante se consideradas as realidades específicas das escolas localizadas nas sociedades tradicionais, que só atendem estudantes dessas sociedades. Do mesmo modo, se consideradas as realidades das escolas localizadas nas sociedades urbanas, que atendem estudantes provenientes dessas sociedades e das sociedades tradicionais (Baptista 2010, p. 680).

Diante disso, cabe à escola buscar formas de inserção da cultura e dos conhecimentos tradicionais na sala de aula, em permanente diálogo com o conhecimento científico. Desta forma, assegurando a transmissão do conhecimento científico, sem deixar de considerar e respeitar nas salas de aula, a cultura local e a valorização do conhecimento tradicional. 
Mas para que o respeito e a inserção do conhecimento tradicional na prática escolar seja uma realidade, é preciso refletir sobre a formação do professor para o ensino de ciências. Essa perspectiva que leva em conta o diálogo de saberes é algo relativamente recente na formação de professores. Em muitos cursos de formação de professores de Biologia, por exemplo, essa discussão é ainda incipiente ou em muitos casos, inexistente. Seixas et al. (2017) afirmam que é preciso refletir sobre a relação do professor com o conhecimento científico, sua importância como mediador no ensino de ciências da natureza e, principalmente, sobre a sua formação inicial e/ou continuada e os conhecimentos que traz consigo. O conhecimento científico deve ser trabalhado de tal forma, que os estudantes se apropriem e aprendam esse conhecimento para a vida e não apenas para momentos específicos, como nos dias de avaliações somativas. Dessa forma, as concepções do professor, que são, na maioria das vezes resultado da sua formação, exercem grande influência sobre a sua prática pedagógica (Feldmann 2009).

De acordo com Baptista (2014), se na formação inicial do professor os conteúdos científicos forem trabalhados como verdades únicas e absolutas, sem provocar o diálogo com outros modos de conhecer e explicar a natureza, isso refletirá na sua prática pedagógica, que será possivelmente cientificista, ou seja, serão considerados apenas os conteúdos trazidos nos livros de ciências, em detrimento do conhecimento prévio dos estudantes. Também poderá haver discussões a respeito do conhecimento tradicional, porém colocando o científico sempre como mais relevante, hierarquizando os saberes, o que também não é desejável. A melhor solução para esse embate é que os professores de ciências sejam mediadores para que os estudantes expliquem os fenômenos naturais à luz da ciência praticada na academia, sem que, precisem romper com suas concepções de mundo, fundamentadas em sua cultura. Mas para isso é preciso que haja uma mudança nos cursos de formação de professores, seja na graduação ou na formação continuada, para que sejam formados profissionais sensíveis ao diálogo intercultural.

O currículo escolar não pode ser algo distante do cotidiano dos estudantes, sendo considerado apenas o resultado do conhecimento construído por outros povos, impelindo aulas que inferiorizam o conhecimento que cada indivíduo traz de sua própria história de vida. Também não se pode valorizar no currículo apenas aquilo que o indivíduo conhece da sua realidade, sem considerar o conhecimento advindo a partir de um método científico; desta forma, não haveria enriquecimento de saberes. Portanto, conhecimento científico e conhecimento tradicional devem se complementar na sala de aula, estabelecendo um diálogo constante, conduzindo a questionamentos a respeito de verdades estabelecidas, conflitos e jogos de poder, sem que haja sobreposição de um tipo de conhecimento sobre outro, mas que seja esclarecido "o lugar" de cada um neste diálogo de saberes.

Diante desse contexto, neste artigo teórico, objetivou-se fazer uma reflexão acerca da importância da inserção do conhecimento tradicional no ensino, nas salas de aula de ciências, como forma de tornar esse processo mais dinâmico e atrativo, aproximando os conhecimentos desenvolvidos por diferentes culturas, na intenção de estabelecer a compreensão e o respeito mútuo entre os membros desses grupos. Buscando a articulação da Etnobiologia com a discussão sobre interculturalidade, este artigo procurará explorar qual a possibilidade de se inserir, no ensino de ciências, outras concepções distintas das apregoadas pela ciência ocidental.

Dentro dessa perspectiva, em termos de pressupostos teóricos-metodológicos que objetivem a inserção de conhecimentos locais no ensino de ciências, este trabalho propõe como referências o pluralismo epistemológico e o construtivismo contextual, conforme defendidos por Cobern (1993). Nesses pressupostos, o autor defende que o conhecimento tradicional deve ser inserido nas aulas de ciências, desde que haja uma demarcação de saberes, pontuando-se aquilo que é oriundo do trabalho científico e o que é conhecimento tradicional. Porém, o professor deve estar atento para não sobrepor o conhecimento científico ao tradicional, deixando claro que estas são apenas formas diferentes de entender a natureza e que podem estabelecer relações entre si, seja em termos de semelhanças e/ou de diferenças epistemológicas (Baptista 2010). 
No ensino de ciências, os conhecimentos prévios dos estudantes são importantes, assim como, o pensamento científico e a apropriação da linguagem científica. Sendo o conhecimento científico um conhecimento socialmente construído pela comunidade científica e recontextualizado para o ambiente escolar, acredita-se que seu ensino deveria pautar-se na problematização, no diálogo, na reflexão e no contexto em que estão inseridos esses estudantes (Seixas et al. 2017).

Paula e Lima (2007) discutem a (im)pertinência do letramento científico à luz da crítica de que as metas da educação em ciências estão para além desse letramento, ou seja, é necessário aprender ciências e sobre as ciências (sua natureza como uma das formas de saber, seus contextos de aplicação e validade). Os autores criticam o ensino focado apenas nos produtos das ciências, o qual inibe diversas contribuições potenciais da educação escolar para a formação de sujeitos críticos e capazes de exercer alguma autonomia intelectual.

A etnobiologia, conforme dito anteriormente, pode ser um recurso importante na iniciação científica Se tivéssemos que apontar um princípio norteador indicativo da postura intelectual que se assume com a Educação científica na Etnobiologia, assumindo a trilogia representada pelas esferas da História, Etnias e Natureza, esse princípio certamente seria o de perscrutar um objeto de estudo em todos os sentidos e direções, apontando os principais aspectos, desdobramentos, virtualidades e virtudes (Medeiros e Valle 2018, p. 2). Em outras palavras, a etnobiologia considera um objeto de estudo sob diferentes pontos de vista, diferentes concepções de mundo.

\section{A Ciência Ocidental}

A ciência ocidental, que surgiu na Grécia Antiga, experimentou grande impulso a partir do século XVII, com um novo enfoque metodológico, promovido, sobretudo, por Renée Descartes, e a perspectiva teórica conhecida como mecanicismo. Métodos científicos são considerados fundamentais para a ciência moderna. Muitos consideram investigações antigas da natureza como sendo pré-científicas. Mas, muito antes da formalização do método científico, o conhecimento produzido no continente europeu já era caracterizado como ciência e foi disseminado entre os povos colonizados como sendo a única verdade absoluta. Muito embora, sob muitos aspectos, o colonizador europeu recorria aos conhecimentos locais do colonizado, para resolver problemas que a própria ciência não dominava. Segundo Marques (1999, p 31), no tocante ao uso de plantas medicinais, por exemplo, muitas plantas descobertas na América portuguesa constituíam-se de espécies e gêneros desconhecidos na Europa, que deram novas perspectivas à terapêutica da época, embora já fossem amplamente utilizados pelos nativos da terra. Segundo a autora, o conhecimento indígena também serviu para inspirar as descobertas científicas do Iluminismo:

\footnotetext{
Homens sem escrita e sem deuses cristãos, os indígenas das terras do pau-brasil eram portadores dos saberes sobre as plantas medicinais existentes. Conhecimento primitivo, desprovido de racionalidade, objetividade, método, cientificidade, enfim, como aludiam os naturalistas, esses saberes norteavam as descobertas científicas dos homens das Luzes. Os europeus encontraram aqui uma série de práticas que extrapolavam seu repertório cultural, porém muito atentaram para os usos empíricos de espécies vegetais feitos pelos ameríndios, aprendendo com esses estranhos e "inferiores", como eles mesmo assinalavam.
}

Costa e Silva (1994) afirmam que a colonização das Américas estabeleceu uma via de mão dupla na troca de informações acerca das plantas para fins medicinais: muitas espécies utilizadas pelos povos nativos das colônias passaram a ser utilizadas também pelos europeus bem como várias espécies foram introduzidas no novo mundo, trazendo consigo a orientação secular do seu uso como medicinal. 
A cultura expansionista e a exploração europeia levaram a ciência ocidental para aquelas terras desconhecidas e seus habitantes, sendo que a interação da ciência com a cultura se deu de forma violenta e desintegradora (Cobern e Loving 2001). A educação colonial projetada para os povos colonizados, usou a ciência como ferramenta para subjugar, modernizar e suplantar a cultura local. O ocidente julgou o resto do mundo por suas próprias escolhas - a ciência, a tecnologia e a educação ocidentais foram usadas para forçar mudanças naquelas sociedades consideradas “deficientes" (Cobern e Loving 2001).

Esse quadro de imposição da ciência ocidental como a única verdade absoluta e capaz de solucionar todos os problemas da humanidade, cerceou as possibilidades de diálogo com as culturas dos povos subjugados, promovendo perdas irreparáveis, que se arrastam pela humanidade até os dias atuais.

A "universalidade da ciência" é outra questão que precisa ser discutida nos espaços de aprendizagem. A proposição de que "a ciência é universal" leva em consideração a chamada "ciência ocidental" praticada nos últimos 300 anos. Isso significa que em todo o mundo onde a ciência é ensinada, há acusações de hegemonia epistemológica e de imperialismo cultural. Não há como negar essa hegemonia e esse imperialismo exercidos pelo mundo ocidental sobre as culturas orientais e até mesmo sobre povos no próprio ocidente, considerados "inferiores". Também não se pode ignorar que o conhecimento científico é fruto de anos, décadas de estudos dentro de métodos considerados "confiáveis" pela comunidade científica e aplicados universalmente. Mas devese considerar que a espécie humana conseguiu evoluir e chegar até a atualidade, ao longo de milhões de anos, sobrevivendo às custas de um conhecimento dito "não científico". Ainda hoje, comunidades tradicionais vivem utilizando conhecimentos não convencionais e, por conseguinte, não científicos.

Com a supremacia do pensamento europeu e da ciência ocidental nos séculos XVIII e XIX, tem havido um efeito desintegrador sobre os valores e formas de representação tradicionais, e uma progressiva cooptação do conhecimento tradicional pela cultura dominante.

Aikenhead (2009) afirma que a ciência, dentro do marco da interculturalidade, é uma subcultura da cultura Ocidental ou Euro Americana. Os cientistas partilham um sistema de significados e de símbolos bem definido, com o qual interagem socialmente. Este sistema foi institucionalizado na Europa Ocidental no século XVII e tornou-se, predominantemente, um sistema de significados e de símbolos ocidental, dominado pelo homem branco de classe média.

De uma forma isolada a ciência ocidental pode ser entendida apenas como uma forma de saber dentre várias outras, cada qual tendo em seu contexto seu alcance e validade. Mas, ao perder de vista as condições e as relações de poder, ou seja, o caráter ideológico da ciência em nossa sociedade contemporânea, estaríamos contribuindo (mesmo que a intenção seja o oposto) para reforçar sua pretensa objetividade e neutralidade (Crepalde e Aguiar Júnior 2014).

Nesse sentido, a ciência ocidental precisa ser reconhecida como uma das formas de saber, uma das formas de abordar a realidade, em meio a uma infinidade de abordagens concebidas por várias culturas. Além disso, deve ser reconhecida como forma hegemônica da civilização ocidental, com seu discurso de poder, sua racionalidade. Sua invisibilidade precisa ser combatida e sempre interrogada criticamente como experiência de descentramento (Crepalde e Aguiar Júnior 2014).

\section{O Conbecimento Tradicional}

O conhecimento tradicional é aquele construído ao longo de milênios por indivíduos dentro das comunidades tradicionais, as quais ainda vivem em contato direto com a natureza e possuem uma estreita dependência desta, para a manutenção do seu modo de vida. O conhecimento tradicional pode ser definido, de acordo com Diegues (2000, p. 30), como "o saber e o saber-fazer a respeito do mundo natural e sobrenatural, gerados no âmbito da sociedade não urbana/industrial, transmitidos oralmente de geração em geração". 
Sob a perspectiva do conhecimento tradicional, a ciência se refere ao conhecimento descritivo da natureza, desenvolvido através da experiência com a mesma. Dessa forma, se defende a existência de muitas diferentes legítimas "ciências". É o conhecimento ecológico descritivo sobre a natureza, adquirido através de longos anos de experiência com o seu ambiente natural, e que tem sido vital para a sobrevivência de muitos povos.

Segundo Toledo (2001, p. 2), existem mais de 300 milhões de pessoas pertencentes a povos e comunidades tradicionais, também chamados de autóctones, minorias ou primeiras nações, dependendo dos critérios de definição. Para Toledo, eles apresentam todos ou parte dos seguintes critérios:

(a) são descendentes dos primeiros habitantes de territórios que foram conquistados durante os Descobrimentos, (b) são povos dos ecossistemas, tais como agricultores, pastores, caçadores, extrativistas, pescadores e ou artesãos que adotam uma estratégia multiuso na apropriação da natureza,(c) praticam formas de produção rural de pequena escala e intensiva em trabalho, produzindo pequenos excedentes, apresentando necessidades satisfeitas com reduzida utilização de energia , (d) não dispõem instituições políticas centralizadas, organizam suas vidas a nível comunitário, tomando decisões em base de consenso,(e) compartilham língua, religião, crenças, vestimenta e outros indicadores de identificação assim como uma relação estreita com seu território. (f) apresentam uma visão de mundo especifica consistindo de uma atitude de proteção e não-materialista em sua relação com a terra e os recursos naturais baseada num intercâmbio simbólico com o mundo natural, (g) são dependentes de uma sociedade e cultura hegemônicas e (h) identificam-se como povos e comunidades tradicionais.

Toledo e Barrera-Bassols (2009) definem "conhecimento tradicional" não apenas como uma "dupla expressão de certa sabedoria (pessoal ou individual e comunitária ou coletiva)", como também uma "síntese histórica e espacial transformada em realidade na mente de um produtor ou de um conjunto de produtores".

Lévi-Strauss (1989), em “O Pensamento Selvagem” enfatiza a atitude de espírito investigativo das populações indígenas, ao afirmar que para elaborar técnicas muitas vezes longas e complexas, que permitem cultivar sem terra ou sem água; transformar grãos ou raízes tóxicas em alimentos, há uma curiosidade assídua e alerta, uma vontade de conhecer pelo prazer de conhecer e pela necessidade, pois apenas uma fração das observações e experiências podia fornecer resultados práticos e imediatamente utilizáveis.

Uma diferença entre o conhecimento científico e o tradicional que deve ser enfatizada, é a forma de comunicação: enquanto o conhecimento científico é através da escrita, o tradicional é comumente transmitido através da oralidade. Segundo Diegues (2000), uma das características das comunidades tradicionais é o fato de possuírem um conhecimento aprofundado da natureza e de seus ciclos e tal conhecimento ser transferido por oralidade de geração em geração.

O saber tradicional conforme afirma Lima (2007) representa um elemento cognitivo que não minimiza o papel da ciência e muito menos aponta para a sua substituição por uma outra, apenas acrescenta que há outros saberes que também analisam os domínios naturais e humanos baseados em outros modos de conhecer.

\section{A Etnobiologia}

As etnociências com os seus recortes vinculados a etnoecologia e a etnobiologia, têm as suas raízes fundamentadas nas propostas científicas realizadas no final do século XIX, que procuravam registrar uma ampla variedade da utilização de plantas e animais pelos membros de diferentes grupos culturais. (Clément 1998).

A etnobiologia recebe contribuições da sociolinguística, da antropologia estrutural e da antropologia cognitiva, sendo, essencialmente, o estudo do conhecimento e das conceituações desenvolvidas por qualquer sociedade a 
respeito do mundo natural, das espécies. É o estudo do papel da natureza no sistema de crenças e de adaptação do homem a determinados ambientes, enfatizando as categorias e conceitos cognitivos utilizados pelos povos em estudo. O conhecimento dos povos tradicionais (indígenas e não-indígenas) não se enquadra em categorias e subdivisões precisamente definidas como as que a biologia tenta, artificialmente organizar (Posey 1987).

A etnobiologia fornece um arcabouço teórico para interligar diferentes áreas das ciências sociais e naturais com outros sistemas de conhecimentos não acadêmicos (Santos-Fita e Costa-Neto, 2007). Ela pode ser também considerada como um dos caminhos possíveis para "conhecermos as pessoas e a maneira como se relacionam com o mundo ao seu redor, não só física, mas também simbólica, cognitiva e afetivamente”(El-Hani, 2001) e ainda procura registrar e traduzir a maneira como cada povo percebe e organiza a natureza. Sendo uma ciência recente, sua teoria e seu método ainda estão em processo de construção.

As concepções sobre ciência e vida ficam comprometidas, sob a perspectiva de um currículo fragmentado e sem as devidas interlocuções. A Etnobiologia representa, sob essa perspectiva, um elemento de articulação entre o conhecimento científico e o tradicional, mais uma vez nos reportando a Baptista (2009, 2010, 2012).

\section{A Demarcação de Saberes no Ensino de Ciências}

O que a comunidade científica considera como "ciência" não deve se sobrepor aos outros domínios do conhecimento. O conhecimento transmitido nas escolas deve enfatizar a importância do conhecimento tradicional e como esse conhecimento muitas vezes serve de base para descobertas científicas e para a nossa vida cotidiana. Ressalte-se que várias pesquisas científicas alimentam-se do conhecimento milenar de comunidades tradicionais. As indústrias farmacêuticas, por exemplo, economizam tempo e recursos financeiros nas etapas das pesquisas, apoderando-se dos conhecimentos empíricos dos povos indígenas ou das comunidades étnicas locais. Como bem afirma Castro et al. (2001, p.19),

A relação entre o conhecimento popular e o conhecimento científico pode ser enquadrada dentro da visão dialética que prevê a transformação e a educação das idéias. $[\ldots] O$ conhecimento científico estabelece uma relação racional entre o uso das plantas medicinais e a cura das doenças. A síntese entre esses dois pontos de vista é alcançada quando os pesquisadores, em busca de novas fontes de substâncias biologicamente ativas, vão até a população para efetuarem levantamentos etnobotânicos e, a partir destes, realizarem pesquisas laboratoriais.

A visão de sociedade "centrada na ciência" ou de "esclarecimento", isto é, a racionalidade científica, certificadora do progresso, postula a ignorância ou irracionalidade dos não especialistas na tomada de decisões, desautorizando suas vozes em assuntos sócio científicos (Irwin 1995; Lima 2011).

Mas, diante do que foi apresentado, qual seria a postura do professor, ao ensinar ciências, levando em consideração o conhecimento tradicional e o científico? Para Cobern e Loving (2001), é importante que os professores levem seus estudantes a entender que há diferentes formas legítimas de pensar sobre a natureza, salientando que cada uma tem seus contextos de utilidade, que nem sempre são iguais. Na visão deles, a cultura local deve ser usada para promover a aprendizagem da ciência. Ao estudar fenômenos da natureza, é importante tratar do fenômeno sob os pontos de vista da ciência e das diferentes culturas, fazendo correlações e enfatizando a contribuição de cada uma para o conhecimento. Os autores defendem que, nas salas de aula cujos saberes culturais dos estudantes são diferentes dos saberes científicos, é importante que o objetivo de ensinar ciências seja, entre outros, a demarcação da ciência, e não a anulação de saberes em prol da ciência.

Segundo Cobern e Loving (2001), não seria vantajoso incorporar os conhecimentos tradicionais à ciência, visto que a ciência ocidental poderia cooptar e dominar o conhecimento tradicional. Este seria diluído na própria 
ciência ocidental, não havendo vantagem para o próprio conhecimento tradicional nesta junção. É melhor que este seja valorizado e transmitido como um tipo diferente de conhecimento, valorizado por seus próprios méritos. A nomenclatura de "científico" não vai "aumentar a importância" do conhecimento tradicional, sendo que este naturalmente já desempenha um papel vital na educação científica, devendo manter uma posição de independência, a ponto de criticar as próprias práticas da ciência e as explicações aceitas para os fenômenos.

Por outro lado, vivemos num paradoxo, pois sabemos que a inclusão do rótulo de "científico" a qualquer tipo de conhecimento, confere a este não apenas poder, mas garantia da transmissão desse conhecimento, controle sobre a educação, acesso a recursos financeiros e influência política. Portanto, deveria haver uma mudança de concepção da própria academia e do poder público no sentido de valorizar outras formas de conhecimento, independentemente do rótulo de "científico", conferindo poder, acesso a financiamentos e garantia de respeito e propagação na educação formal, respeitando cada cultura (Cobern e Loving 2001).

Cobern e Loving (2001) apresentam o "cientificismo" como um problema enfrentado pelo conhecimento ecológico tradicional e por outros domínios do conhecimento, tais como as artes, a literatura e a religião, por causa da hegemonia da ciência. O cientificismo concebe a ciência como a única e legítima forma de se obter e representar o conhecimento verdadeiro da realidade. O problema é que muitas vezes a ciência é usada para dominar os espaços, como se todos os outros discursos fossem de menor valor. Algumas pessoas defendem que a boa saúde, o bem-estar econômico e a segurança nacional dependem exclusivamente da ciência. É claro que são inegáveis os benefícios promovidos pelas inovações tecnológicas fundamentadas na ciência, mas há um certo exagero nestas afirmações. Muitas destas declarações sobre os "benefícios da ciência" omitem, por exemplo, os desastres tecnológicos também produzidos pela própria ciência.

Ao inserir o conhecimento tradicional nas aulas de ciências, a tarefa dos educadores é desenvolver diálogos que valorizem o conhecimento em suas diversas formas e de suas muitas fontes. A inserção do conhecimento tradicional na sala de aula oferece aos estudantes a oportunidade de ver que a prática da ciência pode se beneficiar das visões de outros domínios do conhecimento.

$\mathrm{Na}$ perspectiva de inserção de saberes culturais na sala de aula, nos deparamos com duas concepções: uma que considera que o conhecimento tradicional deve ser ensinado também como uma forma de "conhecimento científico", como argumentam muitos seguidores do multiculturalismo (Ogawa 1995; Krugly-Smolska 1999); e outra que entende que deve haver uma demarcação entre o conhecimento científico e as demais formas de conhecimento, produzidas pelas diversas culturas, enfatizando que esse conhecimento tradicional é uma forma diferente de conhecimento, não menos importante que o conhecimento científico. Esta concepção é conhecida como "Pluralismo Epistemológico".

Para Cobern e Loving (2001), "Pluralismo Epistemológico" não é "relativismo", que considera todos os sistemas de saberes como sendo ciência, tal qual entende-se e pratica-se na atualidade ao redor do mundo, mas o engajamento das comunidades no reconhecimento de nossas diferenças e divergências, e na decisão sobre o que é mais importante em determinadas situações e contextos específicos. O pluralismo epistemológico sustenta a coexistência e o respeito sobre o que realmente importa, que é a verdade, tendo em conta que a verdade nunca está sob um único domínio do conhecimento - nem da ciência.

Baptista (2010, p. 687), nos mostra o caminho para a prática do Pluralismo Epistemológico, afirmando que:

No ensino de ciências, para o Pluralismo Epistemológico, deve haver oportunidades para que os estudantes delimitem, isto é, reconheçam os domínios particulares do discurso em que as suas concepções e as ideias científicas tenham - cada qual no seu contexto -alcance e validade. É preciso criar situações para que os estudantes percebam como a prática da ciência pode se beneficiar dos achados de outros domínios de conhecimento e, do mesmo modo, vejam como algumas das ideias da ciência podem ser alcançadas por outros caminhos epistemológicos. 
Algumas experiências utilizando o diálogo entre conhecimento tradicional e cientifico em sala de aula

Diversos trabalhos relatam experiências didáticas com o uso do conhecimento tradicional dentro da sala de aula. Baptista (2007), em sua pesquisa com estudantes agricultores, do ensino médio, de uma escola pública no município de Coração de Maria-BA, utilizando como conteúdo a morfologia e classificação das Angiospermas, concluiu que a inclusão dos conhecimentos etnobiológicos nas aulas de biologia abriu possibilidades para o diálogo entre os saberes empíricos dos estudantes e os conteúdos do ensino de biologia.

Pérez (2016) desenvolveu um estudo na comunidade turística e pesqueira de Taganga (Magdalena, Colômbia) com a intenção de investigar condições para um diálogo entre conhecimentos tradicionais e conhecimentos científicos escolares no ensino de ciências. $\mathrm{O}$ autor concluiu que o estudo das relações entre o clima e a pesca percebidas pelos pescadores, fornecem luzes para uma melhor compreensão de vias para a representação e interpretação de conhecimentos tradicionais na aula de ciências, assim como do papel destes conhecimentos na promoção de inclusão de ideias não científicas dos estudantes na sala de aula, e um diálogo entre modos de conhecer que contribua para a proteção e conservação de formas de conhecimento não científicas, e a compreensão das ideias e visões científicas escolares.

Bejarano et al. (2014), também em um estudo numa comunidade de estudantes pescadores, observaram que a pesquisa oportunizou um diálogo entre os saberes tradicionais dos estudantes e o conhecimento científico. Tal pesquisa analisou o conhecimento da biologia de crustáceos, de jovens, estudantes de uma escola pública de uma comunidade pesqueira de Baiacu, Bahia, construído através de seu cotidiano na lida com a pesca. Durante a pesquisa os autores verificaram que os saberes tradicionais, apesar de culturalmente relevantes, não estavam sendo levados em conta no desenvolvimento do ensino na escola.

Oliveira (2009) em sua pesquisa a respeito dos saberes de diversas comunidades, concluiu que a comunhão e a convivência, quando pautadas no diálogo e no compromisso mútuo entre profissionais e comunidades, propiciam a apreensão das diversas visões de mundo, ampliação conjunta da compreensão de si e do mundo e a construção de propostas transformadoras mais próximas da concretude da vida das pessoas.

Siqueira e Pereira (2014) realizaram um trabalho com estudantes da disciplina Biologia, do Ensino Médio, sobre os conhecimentos botânicos e etnobotânicos, demonstrando a importância da contextualização do conhecimento e da valorização dos saberes populares. Os autores destacam o movimento positivo que esta atividade gerou na escola e na professora que coordenou a atividade.

Costa et al (2017), em uma pesquisa para analisar como o conhecimento tradicional é estabelecido entre os estudantes e pescadores de determinada região, concluíram que a inclusão do etnoconhecimento no ambiente escolar foi fundamental para o estabelecimento de um diálogo cultural com a ciência, pois, além de propiciar a compreensão da visão dos estudantes sobre a importância ecológica do ecossistema rio-planície de inundação em questão, também contribuiu para a formação de uma atitude crítica e participativa dos mesmos.

Baptista e Araújo (2018) realizaram uma pesquisa baseada num estudo de caso envolvendo licenciandos em biologia de uma universidade pública do estado da Bahia, Brasil, com o objetivo de identificar as influências de experiências práticas envolvendo a etnobiologia aplicada ao ensino de ciências sobre a formação inicial do professor de biologia no que tange ao diálogo de saberes culturais. As autoras verificaram que os licenciandos envolvidos no estudo realizaram reflexões que certamente influenciarão nas suas futuras práticas pedagógicas para que realizem o diálogo cultural da ciência com os saberes dos estudantes. Os resultados da pesquisa também evidenciaram que quando são oferecidas oportunidades de aprendizagem da docência com estratégias e ambientes adequados, a competência para o ensino intercultural poderá ser desenvolvida de maneira significativa. 


\section{A Vida no Currículo}

O currículo, muitas vezes "retrata" a ciência exclusivamente como proveniente de um contexto cultural ocidental. Os assuntos abordados em sala de aula, especialmente no domínio das ciências naturais, muitas vezes são distantes da realidade dos estudantes. Esse distanciamento pode ser resultado do confronto entre os conhecimentos científicos, que são apresentados ao estudante, e os conhecimentos locais, que os estudantes trazem de sua realidade vivenciada, de sua cultura. Diante dessa dicotomia, surgem dificuldades de aprendizado, como a falta de interesse pelo tema e a não aplicabilidade do que é visto na escola em sua vida cotidiana.

A dificuldade encontrada na apreensão da linguagem científica pode estar relacionada a um aprendizado das ciências, com ausência de contexto e de significado, e também à falta de utilidade prática cotidiana desse tipo de conhecimento em suas comunidades. Para professores que trabalham com estudantes provenientes de comunidades tradicionais, "é possível encontrar dificuldades para a comunicação com os estudantes nas salas de aula onde a concepções prévias da maioria deles sejam diferentes das concepções científicas” (Baptista 2010, p. 680).

Segundo Baptista (2010, p. 680-681), "Se consideradas as realidades das escolas localizadas nas sociedades urbanas, que atendem estudantes provenientes dessas sociedades e das sociedades tradicionais, o ensino de ciências - se baseado na supervalorização dos saberes científicos em detrimento dos saberes tradicionais - pode conduzir os estudantes a conflitos entre as explicações científicas e as explicações oriundas dos seus meios socioculturais" e a rejeição por aprender ciência na escola.

Os conhecimentos trabalhados na escola estão intrinsecamente relacionados com questões como ideologia, relações de poder, trajetória, economia, política, aspectos sociais e culturais. Outra questão embutida no currículo é: "Qual o tipo de ser humano desejável para um determinado tipo de sociedade? (Silva 2002). A cada "modelo" de ser humano que se pretende formar, corresponde um tipo de conhecimento, um tipo de currículo.

É importante que os estudantes sejam estimulados a perceber as diferenças, os valores e os contextos apropriados de aplicação dos conhecimentos científicos e dos seus conhecimentos culturalmente fundados, através do diálogo entre diferentes saberes, entre diferentes culturas, nas salas de aula (Cobern 1996).

Para Chassot (2006, p.98), a escola não pode ser vista apenas como repetidora ou reprodutora de conhecimentos, mas deve assumir uma postura mais crítica em relação à educação. O autor complementa: "[...] é preciso abandonar a assepsia. Há a necessidade de tornar o nosso ensino mais sujo, isto é, encharcá-lo na realidade.”

Santomé (1995, p.165) salienta que "[...] os currículos planejados e desenvolvidos nas salas de aula vêm pecando por uma grande parcialidade no momento de definir a cultura legítima, os conteúdos culturais que valem a pena."

Neste sentido, estudos e pesquisas que procuram investigar estratégias e metodologias de ensino que visam resgatar o conhecimento tradicional, num processo de diálogo com o saber científico, são fundamentais para a valorização da cultura popular e tradicional dos envolvidos, tornando o conhecimento algo dinâmico, inacabado, diversificado e mais interessante.

A ideia de que o conhecimento tradicional deve ser trabalhado na sala de aula, está presente no pensamento de diversos autores como Chassot (2006), Lopes (1999), Mortimer (1998), Santomé (1995), Perrelli (2008) e Baptista (2010). Tal inclusão diminuiria o distanciamento entre a educação formal e o cotidiano dos estudantes, além de fornecer contribuições de cada visão de mundo ao conhecimento que está sendo construído. Lopes (1999, p.137) enfatiza que “[...] o conhecimento cotidiano, como todos os demais saberes sociais, faz parte da cultura e é construído pelos homens das gerações adultas, que o transmitem às gerações sucessivas, sendo a escola um dos canais institucionais dessa transmissão."

Nesta mesma perspectiva, Arenas e Cairo (2009) afirmam que o grande desafio da escola moderna está em articular os conhecimentos tradicionais dentro dos currículos escolares convencionais, uma vez que a ciência exerce uma hegemonia epistemológica por meio da escola moderna, condenando e marginalizando qualquer conhecimento alternativo ou cultura local. Para os autores, currículos plurais, que possibilitem o diálogo dos 
saberes, podem, efetivamente, despertar, nos estudantes, valores éticos para que estes possam lidar com os dilemas culturais e problemas socioambientais de sua realidade imediata.

Uma proposta de educação intercultural em ciências parte do reconhecimento da coexistência em um mesmo espaço de diversas culturas ou subculturas. Um indivíduo pode fazer parte de vários grupos ou subgrupos que transitam cotidianamente por várias subculturas (Aikenhead 2009).

\section{Considerações finais}

O conhecimento transmitido na escola é o reflexo daquilo que a sociedade julga ser importante para a formação do ser humano. A escolha dos conteúdos representa um ponto de suma importância no currículo, mas na hora da escolha de determinados temas para as aulas, geralmente são deixados de fora os conhecimentos trazidos pelos estudantes, provenientes de suas diversas culturas, pela não geração de espaços e oportunidades para que eles representem os seus saberes. Essa falta de diálogo da escola com o "conhecimento tradicional" tem transformado as aulas de ciências em espaços fechados para o aprendizado de conhecimentos científicos, desconectados com a realidade, gerando desinteresse e falta de aplicabilidade na vida para os temas estudados.

Ao trabalhar o conhecimento tradicional em sala de aula, o professor deve estar atento ao "cientificismo", tendência a conceber o conhecimento científico como "superior" às demais formas de conhecimento, de forma semelhante à que fomos induzidos, durante os processos de colonização. Por outro lado, seria importante a demarcação do conhecimento, esclarecendo para os estudantes a natureza diferente das formas de conhecimento - o científico, proveniente do trabalho científico com seus métodos próprios e validado por uma determinada comunidade; o tradicional, não menos importante que o científico, fruto das relações de determinados povos com a natureza, responsável pela sobrevivência destes ao longo da história da humanidade. Surge, nesta perspectiva de demarcação do conhecimento, o Pluralismo Epistemológico, o qual tem como premissa discutir como as visões tradicionais diferem das científicas, no contexto das salas de aula de ciências, concepção essa muito importante para a compreensão das diferentes formas de se ver o mundo (Cobern e Loving 2001).

\section{REFERÊNCIAS}

Aikenhead GS. 2009. Educação científica para todos, Lisboa: Edições Pedago, 187 p.

Arenas A, Cairo C. 2009. Etnobotánica, modernidad y pedagogía crítica del lugar. Utopía y Praxis Latinoamericana, 14(44):69-83.

Baptista GCS. 2007. A contribuição da etnobiologia para o ensino e a aprendizagem de ciências: estudo de caso em uma escola pública do estado da Bahia. 188f. Dissertação (Mestrado em Ensino, Filosofia e História das Ciências) Universidade Federal da Bahia, Salvador.

Baptista GCS, El-Hani CN. 2009. The contribution of ethnobiology to the construction of a dialogue between ways of knowing: A case study in a Brazilian public high school. Science \& Education, 18(3-4), 503-520.

Baptista GCS. 2010. Importância da demarcação de saberes no Ensino de Ciências para Sociedades Tradicionais. Ciência e Educação, 16(3):679-694. 
Baptista GCS. 2012. A etnobiologia e sua importância para a formação do professor de ciências sensível à diversidade cultural: indícios de mudanças das concepções de professoras de biologia do estado da Bahia. Tese (Doutorado em Ensino, Filosofia e História das Ciências) - Universidade Federal da Bahia (UFBA) - Universidade Estadual de Feira de Santana (UEFS), Salvador.

Baptista GCS. 2014. Do cientificismo ao diálogo intercultural na formação do professor e ensino de ciências. Revista Interações, 31: 28-53.

Baptista GCS, Araújo GMA. 2018. Desenvolvimento para a competência intercultural na formação do professor de biologia pelas práticas da etnobiologia. Gaia Scientia, 12(2):76-88.

Bejarano NRR, Brunet JMS, Bandeira FPSF, Bartoliero ST. 2014. A vida de alunos pescadores da comunidade de Baiacu (Bahia) e sua relação com a escola: dois mundos distintos? Ciência \& Educação, 20(1):159-173.

Brasil. 2007. Decreto N. 6.040, de 7 de Fevereiro de 2007. Institui a Política Nacional de Desenvolvimento Sustentável dos Povos e Comunidades Tradicionais. Brasília, 7 de fevereiro de 2007.

Castetter EF. 1935. Uncultivated native plants used as sources of food. University of New Mexico. .Biological series, 4(1), University of New Mexico bulletin, whole number 266, Ethnobiological studies in the American Southwest, $62 \mathrm{p}$.

Castro HG, Ferreira FA. 2001. A Dialética do Conhecimento no Uso das Plantas Medicinais. Revista Brasileira de Plantas Medicinais, 3(2):p.19-21.

Chassot A. 2006. Alfabetização científica: questões e desafios para a educação, 4 ed. Ijuí: Ed. Unijuí, 436 p.

Clément D. 1998. The historical foundations of ethnobiology (1860-1899). Journal of Ethnobiology, 18(2):161-187.

Cobern WW. 1993. Contextual constructivism: the impact of culture on the learning and teaching of science. In: K. G. Tobin (Editor). The practice of constructivism in science education. Hillsdale, NJ: Lawrence Erlbaum Associates, Inc., p. 5169.

Cobern WW. 1996. Constructivism and non-Western science education research. International Journal of Science Education, 4 (3): 287-302.

Cobern WW, Loving CC. 2001. Defining "Science" in a Multicultural World: Implications for Science Education. Science Education, 85(1): 50-67.

Costa e Silva A. 1994. O Brasil, a África e o Atlântico no século XIX. Estudos avançados, 8: 21 - 42.

Costa PG, Obara AT, Suzuki HI, Takemoto, RM. 2017. A etnobiologia na sala de aula: os saberes dos alunos do ensino fundamental sobre o Rio Paraná. Vivências, 13(24):10-21.

Crepalde RS, Aguiar Júnior, OG. 2014. Abordagem intercultural na educação em ciências: da energia pensada à energia vivida. Educação em Revista, 30(3): 43-61.

Diegues AC. 2000. Etnoconservação da natureza: enfoques alternativos. In: Diegues, AC (Org.), Etnoconservação: novos rumos para a proteção da natureza nos trópicos. 2 ed., São Paulo: NUPAUB-USP: Hucitec: Annablume, p. 1-46. 
Diegues AC (Org.). 2000. Os saberes tradicionais e a biodiversidade no Brasil. São Paulo: MMA/COBIO/NUPAUB/ USP, $211 \mathrm{p}$.

El-Hani CN. 2001. Por que a etnobiologia e a etnoecologia são importantes? Uma resposta do ponto de vista da educação. In: COSTA-NETO, E. M. \& SOUTO, F. J. B. (Orgs). Anais do I Encontro Baiano de Etnobiologia e Etnoecologia, 91- 108.

Feldmann MG. 2009. Formação de professores e cotidiano escolar. In: Formação de professores e escola na contemporaneidade. São Paulo: Senac São Paulo, p. 71-80.

Guimarães M. 2007. Educação ambiental: participação para além dos muros da escola. In: Mello S S de, Trajber, R. (coord.) Vamos cuidar do Brasil: conceitos e práticas em educação ambiental na escola. Brasília: Ministério da Educação, Coordenação geral de Educação Ambiental: Ministério do Meio Ambiente, Departamento de Educação Ambiental: UNESCO, p. 85-93.

Irwin A. 1995. Ciência cidadã: um estudo das pessoas; especialização e desenvolvimento sustentável. Lisboa: Instituto Piaget, $260 \mathrm{p}$.

Krugly-Smolska E. 1999. Research on multiculturalism applied to students' learning school science: Some theoretical issues. Paper presented at NARST pre-conference, Boston, MA, March. http://www.ouhk.edu.hk/ rcwww/misc/krugly.htm

Levi-Strauss C. 1989. O pensamento selvagem. Campinas: Papyrus Editora, 324 p.

Lima EAC. 2007. Diálogos com a natureza, saberes e estratégias dos povos da floresta. 147f. Tese (Doutorado em Ciências Sociais) - Programa de Pós-graduação em Ciências Sociais, Centro de Ciências Humanas, Letras e Artes, Universidade Federal do Rio Grande do Norte, Natal.

Lima MECC. 2011. Tensões emergentes da educação do campo em torno da construção do conhecimento. In: Simpósio 40 anos do Programa de pós-graduação em Educação da Faculdade de Educação, Belo Horizonte. Palestra... Belo Horizonte: UFMG.

Lopes ARC. 1999. Conhecimento escolar: ciência e cotidiano. Rio de Janeiro: Ed. UERJ, 236 p.

Marques VRB. 1999. Natureza em boiões: medicinas e boticários no Brasil setecentista. Campinas, SP: Editora da Unicamp / Centro de Memória-Unicamp, 350 p.

Medeiros MFT, Valle LS. 2018. Educação Científica e as Relações entre História, Etnias e Natureza, Ethnoscientia, 3(2). D.O.I.: $10.22276 /$ ethnoscientia.v3i2.184

Mortimer EF. 1998. Sobre chamas e cristais: a linguagem cotidiana, a linguagem científica e o ensino de ciências. In: Chassot A, Oliveira R J (Org.), Ciência, ética e cultura na educação, São Leopoldo: Ed. Unisinos, p. 99-118.

Ogawa M. 1995. Science education in a multiscience perspective. Science Education , 79 (5), 583-593

Oliveira MW. 2009. Pesquisa e trabalho profissional como espaços e processos de humanização e de comunhão criadora. Cad. Cedes, 29(79):309-321.

Paula HF, Lima MECC. 2007. Educação em ciências, letramento e cidadania. Química Nova na Escola, 25: 3-9. 
Pérez DFV. 2016. Diálogo entre conhecimentos científicos escolares e tradicionais em aulas de ciências naturais: intervenção e pesquisa na comunidade de Taganga (Magdalena-Colômbia). 331 f. Tese (Doutorado em Ensino, Filosofia e História das Ciências) - Universidade Federal da Bahia, Salvador.

Perrelli MAS. 2008. "Conhecimento tradicional" e currículo multicultural: notas com base em uma experiência com estudantes indígenas Kaiowá/Guarani. Ciência \& Educação, 14(3), 381-396.

Posey D. 1987. Manejo da floresta secundária, capoeiras, campos e cerrados Kayapó. In: Ribeiro B. (org), Suma Etnológica Brasileira. Vol. 1 - Etnobiologia. Petrópolis: Vozes, p. 173-185.

Santomé, JT.1995. As culturas negadas e silenciadas no currículo. In: Silva, T T (Org.), Alienígenas na sala de aula: uma introdução aos estudos culturais em educação, 6 ed, Petrópolis: Vozes, p. 159-177.

Santos-Fita D, Costa-Neto EM. 2007. As interações entre os seres humanos e os animais: a contribuição da etnozoologia. Biotemas, 20(4): 99-110.

Seixas RHM, Calabró L, Sousa DO. 2017. A Formação de professores e os desafios de ensinar Ciências. Revista Thema, 14(1): 289-303. DOI http://dx.doi.org/10.15536/thema.14.2017.289-303.413.

Silva TT. 2002. Documentos e Identidade: Uma Introdução às teorias do Currículo, 2 ed, Belo Horizonte: Autêntica, 156 p.

Siqueira AB, Pereira SM. 2014. Abordagem etnobotânica no ensino de Biologia. Rev. Eletrônica Mestr. Educ. Ambiental, $31(2) 247-260$.

Toledo VM, Barrera-Bassols N. 2009. A etnoecologia: uma ciência pós normal que estuda as sabedorias tradicionais. Desenvolvimento e Meio Ambiente, 20:31-45.

Toledo VM. 2001. Povos / Comunidades Tradicionais e a Biodiversidade. Tradução de Antônio Diegues. In: Levin, S et al., (eds.). Encyclopedia of Biodiversity. México: Academic Press. Disponível em: <http://nupaub.fflch.usp.br/sites/ nupaub.fflch.usp.br/files/VITOR\%20TOLEDO \%20povos\%20e\%20comuniades\%20PRONTO\%20(1).pdf > Acesso em: 09 dez. 2016. 